\title{
Do Physical Activity and COVID-19-Related Anxiety Affect Eating Disorders? Eating disordes and physical activity
}

Somayeh Ahmadabadi ( $\sim$ somayeh.ahmadabadi@gmail.com )

Farhangian University

parisa Sedaghati

University of Guilan

\section{Research Article}

Keywords: Eating disorders, Nutrition knowledge, Anxiety, COVID-19, Physical activity

Posted Date: February 7th, 2022

DOI: https://doi.org/10.21203/rs.3.rs-1278715/v1

License: (c) (i) This work is licensed under a Creative Commons Attribution 4.0 International License.

Read Full License 


\section{Abstract \\ Background}

Eating disorder is one of the most common disorders among adolescents and young females. The present study aimed to investigate the relationship between eating disorders (nutrition attitude) with nutrition knowledge, physical activity level, and COVID-19-related anxiety in female students.

\section{Methods}

The present research was a correlational and causal-comparative study. The statistical population consisted of all female students of Farhangian University of Mashhad (1500 students) in 2021, of whom 247 students were randomly selected. Out of whom, 107 students were active and 140 inactive. Nutrition knowledge, eating disorder, COVID-19-related anxiety, physical activity level, and health-related anthropometric parameters were assessed via the online survey. Statistical analysis was performed using the Kolmogorov-Smirnov test, independent t-test, Pearson correlation, and linear regression in SPSS software.

\section{Results}

The results showed that there was a significant difference between active and inactive students in nutrition knowledge $(P=0.01)$, eating disorders $(P=0.003)$, COVID-19-related anxiety, and physical activity level $(P=0.001)$. Additionally, eating disorders correlated significantly with COVID-19-related anxiety and physical activity level $(P=0.001)$. The linear regression results showed that COVID-19-related anxiety could predict eating disorders in female students $(P=0.001)$. Despite a significant negative correlation between eating disorders and physical activity level, the regression model showed that the latter could not predict the former in female students $(P>0.05)$.

\section{Conclusion}

According to the results, it can be said that in certain conditions, such as the COVID-19 pandemic, increased anxiety levels can increase the prevalence of eating disorders. It seems that regular physical activity can indirectly reduce eating disorders by alleviating anxiety levels.

\section{Key Points}

- Inactive students showed a higher level of Covid-19-related anxiety than active students.

- Only the total score of COVID-19-related anxiety in female students could predict changes in nutrition attitudes or eating disorders 
- $72 \%$ of the students had either eating disorders or poor nutrition attitudes

- The incidence of eating disorders had a significant negative correlation with different dimensions of physical activity.

\section{Introduction}

Eating disorders, such as obesity and anorexia, are serious problems that can impair humans' emotional stability, judgment, and cognitive function and disrupt normal daily functioning [1]. Such disorders have serious effects on the quality of life and psychological, social, and physical states [2]. In recent years, the identification of some factors that can contribute to the development and persistence of eating disorders has directed the attention of researchers toward this field [3]. Studies have indicated an increase in the prevalence of eating disorders even more than previously reported rates, especially among young individuals, particularly young women [4].

Eating disorders might appear at any age; however, they often begin in adolescence and early youth within the age range of $12-25$ years. Nearly $86 \%$ of individuals report the onset of eating disorders in their 20 s when most young individuals enter university, facing numerous challenges and problems in academic, social, and personal life during the transfer from high school to university. Some of the aforementioned problems include adaptation to the university environment, selection of a suitable occupation, communication with peers, and social and psychological adjustments [5]. In this regard, in a study conducted on students, Bernadette reported that about $19 \%$ of girls and $2.3 \%$ of boys had high scores on eating disorders [6].

Moreover, studies show that female students, while reporting physical dissatisfaction and mental obsession with their weight, aspire to lose weight to succeed in social and educational aspects and gain better social acceptance, a phenomenon making them vulnerable to eating disorders [7]. Some female students use unconventional methods to control their weight. Although it is important to control weight for good health and physical attractiveness, excessive focus on this issue leads to symptomatic weight loss and can facilitate the development of eating disorders [8]. Furthermore, several psychological factors, such as anxiety, are important in the pathogenesis of eating disorders. For example, the evidence from clinical studies shows that mood disorders and anxiety can be concomitantly observed in individuals with eating disorders [9]. The evidence also demonstrates that anxiety is strongly associated with eating disorders and abnormal eating behaviors, including dietary restrictions and overeating [10].

Turkani et al. stated in their study (2014) that individuals are responsible for their dietary habits, attitudes, and behaviors during adolescence. In addition, attitudes play an important role in the coherence and persistence of various eating habits and behaviors [11]. However, Kim et al. (2010) investigated the relationship between dietary regimen and physical activity level in students in Seoul, South Korea. In the aforementioned study, the amount of consumed energy was significantly higher in the group of adolescents with moderate physical activity than in the inactive group [12]. On the other hand, Dorindet et al. (2009), in a cross-sectional study, observed no significant association between nutrition knowledge, 
physical activity level, and body mass index (BMI) [13]. However, Basami et al. (2016), in their study on the male athlete students participating in the Student Sports Olympiad, reported a positive and significant relationship between nutrition knowledge and nutrition attitude with nutritional performance [14]. Therefore, a better understanding of the relationship between physical activity and dietary regimen can improve the health-related consequences of unhealthy diets and inactivity, as two important risk factors for human health [15].

Upon the widespread coronavirus disease 2019 (COVID-19) worldwide outbreak, routine physical activities, and exercises have faced difficulties in society. The World Health Organization instructed public health measures, including restricting unnecessary traffic and using sports and recreational facilities, to curb the spread of the virus [16]. Therefore, it seems that these restrictions would create some changes in individuals' behavior, lifestyle, physical activity level, and various daily life aspects. Consequently, the unwanted effects of decreased physical activity and sedentary behaviors become prevalent, exposing individuals to chronic health-related diseases more than before [17]. In this regard, Posinlli et al. (2021) investigated the effects of social distancing during the COVID-19 pandemic on the level of physical activity and its relationship with anxiety and depression, and their results showed that during this period, there was a decrease in the level of physical activity, which was associated with an increase in the prevalence of mood disorders, especially anxiety and depression [18].

At the same time, research has shown that active individuals usually experience less stress, depression, and anxiety than other peers [19]. For this reason, studies have focused on regular physical activity as a potential treatment for depression and anxiety, either as an alternative therapy or in combination with pharmaceutical agents [20].

A certain ratio (around $11.6 \%$ ) of individuals in the community annually develop some forms of anxietyrelated disorders [21]. These individuals are prone to express extreme fear or anxiety in response to perceived threats; accordingly, they develop profound functional dysfunction in the face of specific environmental conditions [22]. Studies have not adequately addressed the anxiety related to the COVID19 pandemic yet; nevertheless, some studies have noted an increase in the prevalence of psychological problems during the pandemic. For example, Ripon et al. showed a surge in post-traumatic stress disorder and depression symptoms during the quarantine, compared to that of the pre-quarantine period, with more severe stress and depression among low-income individuals than others [23].

Various dimensions of the psychological and physiological outcomes of COVID-19, as well as their exacerbating and modulating factors, are still unknown. Therefore, it is essential to evaluate the mental health status of individuals in interaction with their lifestyles during the COVID-19 pandemic. Regarding the increasing prevalence of eating disorders in recent years, especially among female students, it seems necessary to identify the psychological factors directly linked with eating disorders or predispose students to these problems. Therefore, this study aimed to investigate the association of eating disorders (nutrition attitudes) with the levels of nutrition knowledge, physical activity, and COVID-19-related anxiety among female students. 


\section{Methods}

This research was a correlational and causal-comparative study. The statistical population of this study included all 19-25-year-old female students (1500 students) studying at Farhangian University of Mashhad, during the academic year of 2020-2021. The sample size was determined using G-Power software the power of the study is $80 \%$ and with a significance level of $5 \%$, the $95 \%$ confidence interval, based on a previous study [24]. Accordingly, 240 students were selected using the random sampling method, of whom 107 students were active with regular exercise (3 days a week, more than 1 hour each session), and 140 students were inactive.

After obtaining the necessary permissions from the university officials, the online questionnaire link (in the context of Porsline) was provided to students through WhatsApp and Telegram as tools used by the university for the students' online learning. The students were asked to answer all the questions carefully. The online questionnaire consisted of the section of demographic information, The level of physical activity, nutrition knowledge, eating disorders, health-related anthropometric parameters, and COVID-19related anxiety using the Baecke Physical Activity Questionnaire, Eating Attitudes Test, General Nutrition Knowledge Questionnaire, and Corona Disease Anxiety Scale, respectively. At the beginning of the questionnaire, a complete explanation of the research purpose was provided and the students answered the questions after documenting their informed consent to participate in the research. A telephone number and email address were provided to students for any possible questions. In this study, BMI and waist-to-hip ratio (WHR) were used to evaluate health-related anthropometric measures. The BMI is commonly used in epidemiological studies and clinical settings as an index for the assessment of health and body weight [25].

Baecke Physical Activity Questionnaire (BPAQ): This scale includes 16 items and measures the level of physical activity in three sections, namely occupation-related physical activity, sport, and leisure-time physical activity. The scoring is based on a Likert scale from 1 to 5 . The reliability of this tool has been reported within the range of $0.65-0.89$ [26].

General Nutrition Knowledge Questionnaire (GNKQ): This questionnaire was designed by Parmenter and Wardell in 1999, and its validity and reliability ranged from 0.70 to 0.97 [27]. The tool was also validated by Azizi et al. in (2011) [28]. This questionnaire consists of three sections, namely knowledge, attitude, and procedures, with the first section containing 11 items on nutrition knowledge and a total score of 46 .

\section{Eating Attitudes Test (EAT-26)}

This questionnaire was designed by Carner et al. to assess the symptoms of eating disorders and abnormal attitudes and behaviors and identify anorexia nervosa and bulimia nervosa. This scale contains 26 items and three subscales, namely Dieting, Bulimia and Food Preoccupation, and oral control. This tool has relatively good validity and reliability for athletes and non-athletes [29]. The scores are within the range of 0-78, with a score below 20 indicating a usual nutrition attitude and a score of 20 or higher reflecting a disordered (abnormal) nutrition attitude toward eating (i.e., an eating disorder). By 
the application of the Diagnostic and Statistical Manual of Mental Disorders, 4th Edition, criteria, Mintz and Ohaloran reported the validity of this scale as 0.90 for eating disorders [30].

Corona Disease Anxiety Scale: This tool has been developed and validated to assess anxiety due to the spread of the coronavirus in Iran. The final version of this tool consists of 18 items assessing psychological and physical indicators. The tool is scored based on a 4-point Likert scale (never: 0 , sometimes: 1, often: 2 , and always: 3 ), delivering the minimum and maximum scores of 0 and 54, respectively. A higher score in this questionnaire indicates a higher level of anxiety; accordingly, no/mild, moderate, and severe anxiety groups are assigned with the score ranges of 0-16, 17-29, and 30-54, respectively. The reliability of this tool has been reported as 0.919 according to Cronbach's alpha method. The scale consists of items on the rate of studying and searching for news about the coronavirus, close relatives infected with or died due to COVID-19, perceived anxiety about COVID-19, and family communication conflicts during the quarantine [31].

\section{Statistical Analysis}

In the present study, the normal distribution of the data was assessed using the Kolmogorov-Smirnov test. The data were analyzed by the independent t-test. Furthermore, Pearson correlation and linear regression were used to determine correlations between the variables. The SPSS software (version 21) was utilized for statistical analyses, and the significance level was considered 0.01 .

\section{Results}

The results of the Kolmogorov-Smirnov test confirmed the normal distribution of the data. Table 1 shows the participants' demographic characteristics. Out of 247 female students, 107 and 140 subjects were categorized into active and inactive groups, respectively. The age of the participants ranged from 18 to 22 years. There was no significant difference between the two groups (i.e., active and inactive students) in demographic characteristics. 
Table 1

Descriptive Features of Female Students in Active and Inactive Groups

\begin{tabular}{|lll|}
\hline Variables & Active & Inactive \\
\hline $\mathbf{N}$ & 107 & 140 \\
\hline Age & $20.31 \pm 1.22$ & $20.52 \pm 1.46$ \\
\hline Hight & $162.42 \pm 4.83$ & $162.82 \pm 5.72$ \\
\hline Weigth & $55.75 \pm 8.43$ & $55.83 \pm 9.41$ \\
\hline BMI & $21.01 \pm 2.64$ & $21.01 \pm 3.13$ \\
\hline WHR & $0.77 \pm 0.13$ & $0.79 \pm 0.14$ \\
\hline GNK & $31.38 \pm 8.37$ & $28.39 \pm 9.29$ \\
\hline EAT & $25.67 \pm 10.70$ & $29.45 \pm 8.87$ \\
\hline BPAT & $55.27 \pm 9.30$ & $28.22 \pm 16.12$ \\
\hline CDAS & $9.91 \pm 5.35$ & $22.20 \pm 14.09$ \\
\hline GNK: General nutrition knowledge, EAT: Eating Attitudes Test, BPAT: Baecke Physical Activity Total, \\
\hline CDAS: Corona Disease Anxiety Scale \\
\hline
\end{tabular}

Regarding eating disorders, the results of this study showed that 178 students $(72.1 \%)$ had either eating disorders or poor nutrition attitudes; however, 69 students $(27.9 \%)$ had good nutrition attitudes.

Table 2 shows the results of the independent t-test for the comparison of nutrition knowledge, eating disorders, physical activity level, health-related anthropometric measures, and COVID-19-related anxiety between active and inactive students. 
Table 2

Results of the Independent T-test to Determine Differences Between Active and Inactive Students

\begin{tabular}{|c|c|c|c|c|c|c|}
\hline Variables & Groups & $M \pm S D$ & std.error Mean & df & $\mathbf{t}$ & p \\
\hline \multirow[t]{2}{*}{ BMI } & active & $21.01 \pm 2.64$ & \multirow[t]{2}{*}{0.006} & \multirow[t]{2}{*}{245} & \multirow[t]{2}{*}{0.016} & \multirow[t]{2}{*}{0.987} \\
\hline & inactive & $21.01 \pm 3.13$ & & & & \\
\hline \multirow[t]{2}{*}{ WHR } & active & $0.77 \pm 0.13$ & \multirow[t]{2}{*}{-0.015} & \multirow[t]{2}{*}{245} & \multirow[t]{2}{*}{-0.888} & \multirow[t]{2}{*}{0.429} \\
\hline & inactive & $0.79 \pm 0.14$ & & & & \\
\hline \multirow[t]{2}{*}{ GNK } & active & $31.38 \pm 8.37$ & \multirow[t]{2}{*}{2.990} & \multirow[t]{2}{*}{245} & \multirow[t]{2}{*}{2.614} & \multirow[t]{2}{*}{$0.01^{*}$} \\
\hline & inactive & $28.39 \pm 9.29$ & & & & \\
\hline \multirow[t]{2}{*}{ EAT } & active & $25.67 \pm 10.70$ & \multirow[t]{2}{*}{-3.77} & \multirow[t]{2}{*}{245} & \multirow[t]{2}{*}{-3.02} & \multirow[t]{2}{*}{$0.003^{*}$} \\
\hline & inactive & $29.45 \pm 8.87$ & & & & \\
\hline \multirow[t]{2}{*}{ WA } & active & $29.05 \pm 5.05$ & \multirow[t]{2}{*}{14.284} & \multirow[t]{2}{*}{245} & \multirow[t]{2}{*}{17.170} & \multirow[t]{2}{*}{$0.001 *$} \\
\hline & inactive & $14.77 \pm 7.38$ & & & & \\
\hline \multirow[t]{2}{*}{ SA } & active & $14.69 \pm 4.89$ & \multirow[t]{2}{*}{6.863} & \multirow[t]{2}{*}{245} & \multirow[t]{2}{*}{13.850} & \multirow[t]{2}{*}{$0.001 *$} \\
\hline & inactive & $7.82 \pm 4.58$ & & & & \\
\hline \multirow[t]{2}{*}{ LA } & active & $11.78 \pm 2.43$ & \multirow[t]{2}{*}{5.699} & \multirow[t]{2}{*}{245} & \multirow[t]{2}{*}{10.446} & \multirow[t]{2}{*}{$0.001^{*}$} \\
\hline & inactive & $6.08 \pm 5.22$ & & & & \\
\hline BPAT & active & $55.27 \pm 9.30$ & 27.049 & 245 & 15.492 & 0.001 \\
\hline & inactive & $28.22 \pm 16.12$ & & & & \\
\hline CDAS & active & $9.91 \pm 5.35$ & -12.284 & 245 & -8.553 & $0.001 *$ \\
\hline & inactive & $22.20 \pm 14.09$ & & & & \\
\hline * $P<0.01$ & & & & & & \\
\hline $\begin{array}{l}\text { BMl: Body } \\
\text { Attitudes T } \\
\text { Activity To }\end{array}$ & $\begin{array}{l}\text { s Index, I } \\
\text { SA: Sport }\end{array}$ & $\begin{array}{l}\text { Waist-to-hip } \\
\text { ivity, WA: Wor }\end{array}$ & $\begin{array}{l}\text { GNK: General Nu } \\
\text { vity, LA: Leisure }\end{array}$ & $\begin{array}{l}\text { n Kno } \\
\text { ty, BP }\end{array}$ & $\begin{array}{l}\text { dge, EAT } \\
\text { Baecke }\end{array}$ & $\begin{array}{l}\text { ting } \\
\text { sical }\end{array}$ \\
\hline
\end{tabular}

Table 3 tabulates the results of correlation analysis between the research variables in all female students. The level of physical activity significantly correlated with the WHR, nutrition knowledge, eating disorders, and COVID-19-related anxiety in female students. In addition, COVID-19-related anxiety significantly correlated with eating disorders $(P<0.05)$. 
Table 3

Correlation Between Research Variables in Female Students Participating in This Study

\begin{tabular}{|c|c|c|c|c|}
\hline Variables & BPAT & & CDAS & \\
\hline & $r$ & $p$ & $r$ & $p$ \\
\hline WHR & -0.0161 & $0.011^{\star}$ & -0.038 & 0.548 \\
\hline BMI & 0.011 & 0.862 & -0.047 & 0.463 \\
\hline GNK & 0.195 & $0.002^{\star \star}$ & 0.082 & 0.199 \\
\hline EAT & -0.200 & $0.002^{\star \star}$ & 0.281 & $0.001^{\star \star}$ \\
\hline CDAS & -0.412 & $0.001^{\star \star}$ & - & \\
\hline \multicolumn{5}{|c|}{$\star P<0.05, \star \star P<0.01$} \\
\hline
\end{tabular}

Table 4 shows that eating disorders significantly correlated with COVID-19-related anxiety and different dimensions of physical activity in female students $(P<0.05)$. However, there was no significant correlation between eating disorders and nutrition knowledge $(P>0.05)$.

Table 4

Correlation of Eating Disorders With Different Dimensions of Physical Activity and Nutrition Knowledge

\begin{tabular}{|lll|}
\hline Variables & EAT & \\
\hline & $\mathbf{r}$ & $\mathrm{p}$ \\
\hline CDAS & 0.281 & $0.001^{\star}$ \\
\hline GNK & -0.070 & 0.273 \\
\hline BPAT & -0.200 & $0.002^{\star}$ \\
\hline WA & -0.206 & $0.001^{*}$ \\
\hline SA & -0.170 & 0.007 \\
\hline LA & -0.173 & 0.006 \\
\hline * P<0.01 & & \\
\hline EAT: Eating Attitudes Test, CDAS: Corona Disease Anxiety Scale, GNK: General Nutrition Knowledge, \\
\hline BPAT: Baecke Physical Activity Total, WA: Work Activity, SA: Sports Activity, LA: Leisure Activity. \\
\hline
\end{tabular}


According to Table 4-1,2, the results of the analysis of variance (ANOVA) showed that there was a significant relationship between predictor and criterion variables $(F=4.443 ; P<0.001)$. The results of ANOVA and regression statistics showed that $10 \%$ of the variance of eating disorders or nutrition attitudes in female students could be explained by anxiety $\left(R^{2}=0.1\right)$. The beta coefficient of anxiety $(\beta=$ $0.259)$ showed that this variable could predict the variance of eating disorders in female students with $95 \%$ confidence, indicating a relationship between an increase in anxiety level and the incidence of eating disorders in female students.

Table 4-1. Summary of Regression Model and Analysis of Variance Results

\begin{tabular}{ccccc} 
Variables & $\mathbf{R}$ & $\mathbf{R}^{2}$ & F-value & P-value \\
\hline EAT & 0.316 & 0.100 & 4.443 & $0.001^{*}$ \\
\hline
\end{tabular}

$* \mathrm{P}<0.01$

EAT: Eating Attitudes Test.

Table 4-2. Results of Regression Model Analysis Between COVID-19-related Anxiety and Physical Activity Level

\begin{tabular}{cccccc} 
Variables & B & SE & Beta & T & p \\
\hline Constant & 27.261 & 2.827 & & 9.642 & $0.001^{*}$ \\
\hline CDAS & 0.201 & 0.054 & 0.259 & 3.795 & $0.001^{*}$ \\
\hline BPAT & -0.142 & 0.332 & -0.274 & -0.427 & 0.670 \\
\hline WA & -0.072 & 0.451 & -0.070 & -0.160 & 0.873 \\
\hline SA & 0.674 & 0.426 & 0.351 & 1.584 & 0.114 \\
\hline LA & -0.161 & 0.356 & -0.083 & -0.451 & 0.652 \\
\hline GNK & -0.053 & -0.069 & -0.049 & -0.769 & 0.443 \\
\hline
\end{tabular}

* $\mathrm{P}<0.01$

Predictor variables: Coronavirus-disease-2019-related anxiety, physical activity level, and nutrition knowledge Criterion variable: Eating disorders

\section{Discussion}

The results of the present study showed that the differences in the means of health-related anthropometric indices (i.e., BMI and WHR) were not statistically significant between active and inactive female students. However, there were significant differences between active and inactive students regarding COVID-19-related anxiety, occupation-related physical activity, sports physical activity, leisuretime physical activity, and overall physical activity. Correlation analysis demonstrated that the incidence of eating disorders had a significant negative correlation with different dimensions of physical activity and a significant positive correlation with COVID-19 anxiety. Additionally, the overall physical activity correlated significantly and negatively with the WHR and COVID-19 anxiety and directly with nutrition knowledge. 
The regression model results presented to predict eating disorders in female students based on the level of physical activity and COVID-19-related anxiety revealed that only the latter could predict eating disorders or nutrition attitudes among the participants. In other words, an increase in the level of COVID19-related anxiety in female students was associated with the elevated risk of eating disorders and could predict changes in nutrition attitudes or eating disorders. The aforementioned results are similar to the results of a study performed by Thomas et al. examining the relationship between nutrition attitudes or eating disorders and mood among high school students in the UK [32]. Moreover, Mollazadeh Esfahani et al., who assessed the relationship between mental health and eating disorders in the female students of Guilan University, Iran, highlighted the predictive role of anxiety in eating disorders [33].

Furthermore, the present study's findings regarding the $72.1 \%$ prevalence of poor nutrition attitudes or eating disorders among female students are in line with girls' propensity to eating disorders. However, some researchers believe that anxiety disorders precede and might predispose individuals to eating disorders. Nevertheless, others believe that psychological disorders, such as anxiety and depression, might appear during periods of malnutrition and be the consequences of severe malnutrition $[34,35]$.

Regarding the link between anxiety and eating disorders among women, it seems that anxiety disorders can predispose them to anorexia nervosa. In addition, fear of gaining weight and subsequently avoiding eating are important factors involved in the pathogenesis of eating disorders. Limitations in calorie intake can also be stressful for these individuals. These hypotheses are supported by neurological biological processes, as an increase in serotonin has been noted to increase anxiety and decrease appetite. On the other hand, a decrease in serotonin during starvation can reduce anxiety; therefore, the restarting of eating can elevate serotonin levels and anxiety [34].

In some studies, Ahmadabadi (2021)[36] and Chang et al. (2020)[37] examined the mental health status and its effective factors in students during the COVID-19 pandemic. The aforementioned study showed that the overall rate of anxiety was $26.60 \%$, and the rates of mild, moderate, and severe anxiety were $23.19 \%, 2.71 \%$, and $0.70 \%$, respectively. Moreover, the results of the present study demonstrated that there was a significant difference in COVID-19-related anxiety between active and inactive students, with a higher level of COVID-19-related anxiety in inactive than in active students. Therefore, the anti-anxiety effects of exercise based on various biological mechanisms can be considered. For example, exercise can improve physical fitness, modulate the levels of the neurotransmitters involved in anxiety and the hormones participating in stress development, and reduce muscle tension. Additionally, from a psychological point of view, the increased physical activity level following exercise can boost Positive reinforcement following a response and create a condition to distract the individual from threatening and stressful situations, such as disease outbreaks, paving the way for the reinforcement of self-confidence and self-empowerment and mitigating anxiety [38].

The results of this study showed that in addition to the overall level of daily physical activity, there were significant differences in occupation-related physical activity, sport, and leisure-time physical activity between active and inactive students. The aforementioned results are consistent with the results of 
studies indicating the inadequate physical mobility and physical weakness of most students in some universities [39]. In this regard, the findings of a study performed by Tehrani et al. showed that individuals could benefit from physical and health advantages and develop their psychological and social functions by performing appropriate physical activities and participating in sports programs [40]. Immobility has been noted as one of the factors involved in the development of psychological and mental disorders, and numerous studies have confirmed a high prevalence of psychological disorders among sedentary individuals [41].

Mental health is one of the indicators for the assessment of the community, and the adolescence and youth periods are critical phases in the process of human development [42]. Physical activity is an essential tool for the improvement of public health; nevertheless, few studies have addressed the relationship between physical activity and mental health $[43,44]$.

Some of the limitations of this study were the lack of access to an equal number of active and inactive students and the precise control of other factors affecting students' health in addition to anxiety. Also, This study could not collect data from all campuses of Farhangian University, only one campus of Mashhad was chosen for this study. Future research should consider different groups of people to evaluate important factors affecting health in the COVID-19 pandemic.

\section{Conclusions}

Students are prone to lose their mental health due to various factors and the special conditions facing them, such as being away from the family, entering large and stressful environments, financial problems, and great volumes of courses. Particularly, during the post-coronavirus era, a heavy burden of disturbing and stressful news and students' anxiety of themselves or their relatives contracting the disease and suffering its consequences can further endanger students' mental health. The primary goal of public mental health is to help everyone achieve a better, happier, and more coherent life and better understand and prevent mood, emotional, and behavioral disorders; therefore, the prevention of psychological disorders to create a healthy society is one of the educational system's main duties; this goal will be achieved by encouraging individuals, especially students who are themselves the cornerstone of the educational system, to modify their sedentary lifestyles by performing appropriate levels of physical activity.

\section{Declarations}

\section{Acknowledgements}

The authors gratefully thank all volunteers who participated and cooperated in this study

\section{Ethics approval and consent to participate}


This study was approved and registered with the ethics code IR.MUMS.REC.1400.217 in the Research ethics committees of Mashhad University of Medical Sciences in Iran.

\section{Authors' Contributions}

SA was a major contributor in writing the manuscript. PS helped in the analysis of data and methodology.

The authors read and approved the final manuscript.

\section{Funding statement}

This study is taken from the research project funded by the Farhangian University, Khorasan Razavi Province, Iran (Grant number 51100/996/400).

\section{Ethics approval and consent to participate}

This study was approved and registered with the ethics code IR.MUMS.REC.1400.217 in the Research ethics committees of Mashhad University of Medical Sciences in Iran. All the participants completed and signed informed consent.

\section{Consent for publication}

All authors have agreed to published the manuscript in its current form.

\section{Competing interests}

The authors declare that they have no competing interests

\section{Author details}

${ }^{1}$ Department of Physical Education and Sports Sciences, Farhangian University, Tehran, Iran.

${ }^{2}$ Faculty of Physical Education and Sports Sciences, University of Guilan, Rasht, Iran

\section{References}

1. Klump KL, Bulik CM, Kaye WH, Treasure J, Tyson E: Academy for eating disorders position paper: eating disorders are serious mental illnesses. International Journal of Eating Disorders 2009, 42:97103.

2. Leung SF, Ma JLC, Russell J: Enhancing quality of life in people with disordered eating using an online self-help programme. Journal of eating disorders 2013, 1:1-11.

3. Brown AJ, Parman KM, Rudat DA, Craighead LW: Disordered eating, perfectionism, and food rules. Eating behaviors 2012, 13:347-353.

4. White S, Reynolds-Malear JB, Cordero E: Disordered eating and the use of unhealthy weight control methods in college students: 1995, 2002, and 2008. Eating disorders 2011, 19:323-334. 
5. Kanekoa ML: The Correlation Between the Eating Attitudes Test and Body Shape Questionnaire. Brigham Young University; 2007.

6. Bernadette PC: Associations among selfreported disordered eating behavior, nutrient intake, depression, and self-efficacy among college students. Published to the graduate college of the bowling green state university 2007:8-157.

7. Schwitzer $A$, Rodriguez $L$ : Understanding and responding to eating disorders among college women during the first-college year. Journal of the First-Year Experience \& Students in Transition 2002, $14: 41-63$.

8. Wade TD, Keski-Rahkonen A, Hudson Jl: Epidemiology of eating disorders. Textbook of psychiatric epidemiology 2011:343-360.

9. Hudson JI, Hiripi E, Pope HG, Kessler RC: " The prevalence and correlates of eating disorders in the national comorbidity survey replication": Erratum. 2012.

10. Fitzsimmons EE, Bardone-Cone AM: Coping and social support as potential moderators of the relation between anxiety and eating disorder symptomatology. Eating behaviors 2011, 12:21-28.

11. Turconi G, Guarcello M, Maccarini L, Cignoli F, Setti S, Bazzano R, Roggi C: Eating habits and behaviors, physical activity, nutritional and food safety knowledge and beliefs in an adolescent Italian population. Journal of the American College of Nutrition 2008, 27:31-43.

12. Kim Y, Kim HA, Kim J-H, Kim Y, Lim Y: Dietary intake based on physical activity level in Korean elementary school students. Nutrition research and practice 2010, 4:317-322.

13. De Vriendt T, Matthys C, Verbeke W, Pynaert I, De Henauw S: Determinants of nutrition knowledge in young and middle-aged Belgian women and the association with their dietary behaviour. Appetite 2009, 52:788-792.

14. Bassami M EKMA: Knowledge, attitude and nutritional performance of male student-athletes participating in the Student Sports Olympiad in 2014. Journal of Sport and Exercise Physiology 2016, 9:1345-1354.

15. Stang JS, Stotmeister B: Nutrition in adolescence. In Nutrition Guide for Physicians and Related Healthcare Professionals. Springer; 2017: 29-39

16. Freeman S, Eykelbosh A: COVID-19 and outdoor safety: Considerations for use of outdoor recreational spaces. J National Collaborating Centre for Environmental Health 2020.

17. Chen P, Mao L, Nassis GP, Harmer P, Ainsworth B, Li FJJos, science h: Returning Chinese school-aged children and adolescents to physical activity in the wake of COVID-19: Actions and precautions. Sport Health Sci 2020, 9:103-104.

18. Puccinelli PJ, da Costa TS, Seffrin A, de Lira CAB, Vancini RL, Nikolaidis PT, Knechtle B, Rosemann T, Hill L, Andrade MS: Reduced level of physical activity during COVID-19 pandemic is associated with depression and anxiety levels: an internet-based survey. BMC Public Health 2021, 21:1-11.

19. Chekroud SR, Gueorguieva R, Zheutlin AB, Paulus M, Krumholz HM, Krystal JH, Chekroud AM: Association between physical exercise and mental health in 1.2 million individuals in the USA between 2011 and 2015: a cross-sectional study. J The Lancet Psychiatry 2018, 5:739-746. 
20. Carek PJ, Laibstain SE, Carek SM: Exercise for the treatment of depression and anxiety. J The international journal of psychiatry in medicine 2011, 41:15-28.

21. Babaei S NE, Derakhti.: Study of the relationship between regular physical activity and social anxiety in obese women. SJNMP 2019, 4:16-24.

22. Baxter AJ, Scott K, Vos T, Whiteford HJPm: Global prevalence of anxiety disorders: a systematic review and meta-regression. 2013, 43:897.

23. Ripon RK, Mim SS, Puente AE, Hossain S, Babor MMH, Sohan SA, Islam N: COVID-19: psychological effects on a COVID-19 quarantined population in Bangladesh. Heliyon 2020, 6:e05481.

24. Davar V: Nutritional knowledge and attitudes towards healthy eating of college-going women hockey players. Journal of Human Ecology 2012, 37:119-124.

25. Sedaghati P: Applied Kinetropropetry. 2017.

26. Pols MA, Peeters PH, Bueno-de-Mesquita HB, Ocke MC, Wentink CA, Kemper HC, Collette HJ: Validity and repeatability of a modified Baecke questionnaire on physical activity. International journal of epidemiology 1995, 24:381-388.

27. Costarelli V, Stamou D: Emotional intelligence, body image and disordered eating attitudes in combat sport athletes. Journal of Exercise Science \& Fitness 2009, 7:104-111.

28. Azizi M, Aghaee N, Ebrahimi M, Ranjbar K: Nutrition knowledge, the attitude and practices of college students. Facta Universitatis: Series Physical Education and Sport 2011, 9:349-357.

29. Rivas $T$, Bersabé $R$, Jiménez $M$, Berrocal $C$ : The eating attitudes test (EAT-26): reliability and validity in Spanish female samples. The Spanish journal of psychology 2010, 13:1044-1056.

30. Mintz LB, O'Halloran MS: The Eating Attitudes Test: validation with DSM-IV eating disorder criteria. Journal of personality assessment 2000, 74:489-503.

31. Alipour A, Ghadami A, Alipour Z, Abdollahzadeh H: Preliminary validation of the Corona Disease Anxiety Scale (CDAS) in the Iranian sample. J Quarterly Journal of Health Psychology 2020, 8:163175.

32. Thomas $\mathrm{CL}$, James AC, Bachmann MO: Eating attitudes in English secondary school students: Influences of ethnicity, gender, mood, and social class. International Journal of Eating Disorders 2002, 31:92-96.

33. Mollazadeh Esfanjani R, Kafi SM, Yegane T: Relationship between mental health and eating disorders in female students of Guilan University. Journal of Inflammatory Disease 2013, 16:54-60.

34. Kaye WH, Bulik CM, Thornton L, Barbarich N, Masters K, Group PFC: Comorbidity of anxiety disorders with anorexia and bulimia nervosa. American Journal of Psychiatry 2004, 161:2215-2221.

35. Godart NT, Flament MF, Perdereau F, Jeammet P: Comorbidity between eating disorders and anxiety disorders: a review. International Journal of Eating Disorders 2002, 32:253-270.

36. Ahmadabadi S: Comparison of General-Social Health and Corona-Induced Anxiety Between Active and Inactive Students in the COVID-19 Pandemic. Frontiers in Psychiatry 2021, 12. 
37. Chang J, Yuan Y, Wang D: Mental health status and its influencing factors among college students during the epidemic of COVID-19. Nan fang yi ke da xue xue bao= Journal of Southern Medical University 2020, 40:171-176.

38. Dowling K: Nutrition Knowledge of Division I Tennis and Cross-Country Collegiate Athletes at Coastal Carolina University. 2011.

39. Poissonnet C-M, Iwatsubo Y, Cosquer M, Salva M-AQ, Caillard J-F, VERON M: Across-sectional study of the health effects of work schedules on $\mathbf{3 2 1 2}$ hospital workers in france: implications for the new french work schedules policy. Journal of human ergology 2001, 30:387-391.

40. Tehrani H, Vahedian Shahroodi M, Fadayevatan R, Abusalehi A, Esmaeili HJJoH, Development: Mental Health Status and its Related Factors in Elderly People Residing in Nursing Homes of Mashhad, Iran. J Journal of Health 2017, 6:171-181.

41. Arent SM, Landers DM, Etnier JL, Activity $p$ : The effects of exercise on mood in older adults: A metaanalytic review. J Journal of Aging 2000, 8:407-430.

42. Bolognini M, Plancherel B, Nunez R, Bettschart WJRDeedSP: Assessment of the effects of age at start of puberty on mental health in pre-adolescence: results of a longitudinal study (1989-1991). J Revue D'epidemiologie et de Sante Publique 1993, 41:337-345.

43. Peluso MAM, Andrade LHSGdJC: Physical activity and mental health: the association between exercise and mood. J Clinics 2005, 60:61-70.

44. De Moor MH, Boomsma DI, Stubbe JH, Willemsen G, de Geus EJJAogp: Testing causality in the association between regular exercise and symptoms of anxiety and depression. J Archives of general psychiatry 2008, 65:897-905. 